CLINICAL STUDY

\title{
Long-acting pegylated human GH in children with GH deficiency: a single-dose, dose-escalation trial investigating safety, tolerability, pharmacokinetics and pharmacodynamics
}

\author{
Jean de Schepper ${ }^{1,2}$, Michael Højby Rasmussen ${ }^{3}$, Zoran Gucev ${ }^{4}$, Alon Eliakim ${ }^{5}$ and Tadej Battelino ${ }^{6}$ \\ ${ }^{1}$ UZ Brussel, Department of Pediatrics Laarbeeklaan 101, 1090 Brussels, Belgium, ${ }^{2}$ UZ Gent, Department of Pediatrics, De Pintelaan, 185,9000 Ghent, \\ Belgium, ${ }^{3}$ Global Development, Novo Nordisk A/S, Krogshøjvej 55, DK-2880 Bagsvard, Denmark, ${ }^{4}$ Clinic of Children Diseases, Skopje Vodnjanska 17 , \\ 1000 Skopje, Macedonia, ${ }^{5}$ Department of Pediatrics, Meir Medical Center, 44281 Kfar Saba, Israel and ${ }^{6}$ Department of Paediatric Endocrinology, Diabetes \\ and Metabolism, University Children's Hospital, Bohoričeva 20, 1000 Ljubljana, Slovenia
}

(Correspondence should be addressed to M H Rasmussen; Email: mhr@novonordisk.com)

\begin{abstract}
Objective: GH replacement therapy currently requires daily injections, which may be inconvenient and distressing for young patients. This study determined the safety, tolerability, pharmacokinetics and pharmacodynamics of escalating single doses of a pegylated GH (NNC126-0083) developed for onceweekly administration, in children with GH deficiency (GHD).

Design and methods: Thirty children (age $\geq 6$ and $\leq 12$ years, weight $\geq 16 \mathrm{~kg}$ ) were randomised to NNC126-0083 or daily GH treatment. The subjects discontinued their daily GH treatment 7-9 days before receiving NNC126-0083 at $0.01,0.02,0.04$ or $0.06 \mathrm{mg}$ protein $/ \mathrm{kg}(n=22)$ or seven once-daily doses of $\mathrm{GH}$ at $0.035 \mathrm{mg}$ protein $/ \mathrm{kg}(n=8)$.

Results: NNC126-0083 was well tolerated, and no short-term safety or local tolerability issues were identified. After NNC126-0083 treatment, dose-dependent IGF1 increases were evident for maximum concentration $\left(C_{\text {max }}\right)$, but not area under the curve $\left(\mathrm{AUC}_{0-168 \mathrm{~h}}\right)$. Mean values for IGF1 $\mathrm{AUC}_{0-168 \mathrm{~h}} / 168 \mathrm{~h}$ and $C_{\max }$ were higher for $\mathrm{GH}$ than for NNC126-0083, although the difference was not statistically significant for cohort's $0.06 \mathrm{mg}$ protein $/ \mathrm{kg}$. At $0.06 \mathrm{mg}$ protein $/ \mathrm{kg}$, the resulting IGF1 response began subsiding at $\sim 3$ days post-dose.

Conclusion: Single doses of long-acting NNC126-0083 were safe and well tolerated in children with GHD. Increased IGF1 levels were observed in all NNC126-0083 dose groups; however, a satisfactory once-weekly IGF1 profile was not reached within the NNC126-0083 dose levels administered.
\end{abstract}

European Journal of Endocrinology 165 401-409

\section{Introduction}

GH deficiency (GHD) in paediatric and adult patients currently necessitates many years or lifelong treatment and persistence with a daily s.c. injection regimen. Studies investigating compliance have shown that approximately one-fourth of children on $\mathrm{GH}$ treatment miss more than two injections per week $(1,2)$ and that low compliance can be partly attributed to difficulties with injections (3). A long-acting GH preparation allowing for reduced injection frequency is likely to improve treatment adherence and to reduce the inconvenience and distress associated with daily injections. Results from studies on children and adults with GHD, comparing the continuous GH infusion using a s.c. pump versus intermittent daily s.c. administrations of $\mathrm{GH}$, demonstrate the same growth rate in children and same effect on body composition in adult patients $(4,5)$.
NNC126-0083 is a pegylated GH, consisting of a $43 \mathrm{kDa}$ polyethylene glycol residue attached to glutamine 141 of the recombinant human GH (rhGH) molecule, and is intended for once-weekly s.c. injection. The pegylation of a protein generally results in prolongation of the in vivo mean residence time, mainly through reduced clearance by filtration in the kidneys (prolonged elimination phase) and a slower absorption. The safety, pharmacokinetic (PK) and pharmacodynamic (PD) profiles of NNC126-0083 obtained in recent single- and multiple-dose clinical trials have shown that NNC126-0083 is well tolerated by both healthy adults and adults with GHD and that the compound possesses a potential once-weekly treatment profile $(6-8)$. We report here the first data on once-weekly administration of NNC126-0083 to children with GHD and how the generated profiles on safety, PK and PD compared to profiles obtained in children after seven once-daily doses of GH. 


\section{Subjects and methods}

\section{Subjects}

Pre-pubertal boys and girls (age: $\geq 6$ and $\leq 12$ years except for France: $\geq 9$ and $\leq 12$ years; body weight $\geq 16 \mathrm{~kg}$ except for France: $\geq 25 \mathrm{~kg}$ ) with a confirmed diagnosis of GH insufficiency based on two different $\mathrm{GH}$ provocation tests, defined as a peak of $\mathrm{GH}$ level $<7 \mathrm{ng} / \mathrm{ml}$, were enrolled as subjects in this study. For children with three or more pituitary hormone deficiencies, only one $\mathrm{GH}$ provocation test was needed. In accordance with country-specific practice, GHD was defined by only one GH provocation test, defined as a peak of GH level $<7 \mathrm{ng} / \mathrm{ml}$. No auxological or radiological data were obtained in this study, but have been obtained prior to initiation of $\mathrm{GH}$ replacement outside the current study in accordance with countryspecific practice. In addition to having a GH response below $7 \mathrm{ng} / \mathrm{ml}$ during provocative test(s), all GHD subjects included in the study were diagnosed as GHD by the investigators and in accordance with national requirements for diagnosing GHD. The subjects received GH replacement treatment for at least 3 months and discontinued their treatment between 7 and 9 days before receiving the trial product. The protocol was approved by the local and national ethics committees as appropriate and conducted in accordance with the ICH guidelines for Good Clinical Practice (9) and the Declaration of Helsinki (10). Written informed consent was obtained prior to all trial-related activities.

\section{Trial design and procedures}

The trial was designed as a single-dose, dose-escalation trial, investigating the safety, tolerability, PK and PD of NNC126-0083 in children with GHD. The subjects were randomised to treatment with either a single dose of NNC126-0083 or 7 days of once-daily injections of GH (Norditropin). NNC126-0083 was investigated at four different dose levels: $0.01,0.02,0.04$ and $0.06 \mathrm{mg}$ protein $/ \mathrm{kg}$, and GH was given at $0.035 \mathrm{mg} / \mathrm{kg}$ per day (upper approved dose level for daily Norditropin treatment). The subjects were randomised at the day of treatment by means of a telephone-based system to receive treatment with either $\mathrm{NNC126-0083} \mathrm{or} \mathrm{GH.}$ The dose level allocation (for NNC126-0083) was not randomised. The randomisation to the NNC126-0083 and GH group for each dose level was carried out in a 3:1 manner.

The subjects attended a screening visit (visit 1), followed by a GH washout period of $7(+2)$ days immediately before the first injection with trial product at visit 2 . The visit 2 involved a 4-day in-house stay, followed by a 7-day ex-house period and a final follow-up visit scheduled 27-31 days after the first injection with the trial product. NNC126-0083 was administered as a single s.c. dose in the thigh, using a standard syringe.
GH (somatropin; Norditropin) was administered once daily for 7 days, using a single-use pre-filled pen (NordiFlex). Progress to the next higher dose level in a new cohort of subjects took place after evaluation by an internal safety assessment group. All GHD subjects were recruited from paediatric endocrine units (please refer to the acknowledgements section). All subjects completed a follow-up visit to the clinics 3-4 weeks after dosing.

\section{Safety}

The safety of NNC126-0083 and GH was assessed on the basis of data on adverse events, clinical laboratory measurements (haematology, biochemistry, urinalysis, fasting blood glucose, fasting blood insulin and antibodies), physical examinations, vital signs, body weight, electrocardiogram and injection site tolerability. The latter was evaluated by manual, visual inspection of injection sites, assessing the occurrence of pain, tenderness, itching, rash, redness, induration and any other signs of injection site reactions.

\section{$P K$ and PD sample collection and analytical methodology}

Blood samples for PK and PD assessments were performed $30 \mathrm{~min}$ prior to the first treatment injection, at the time for (first) injection; $15 \mathrm{~min}, 1,2,4,6$ and $8 \mathrm{~h}$ post-dose and every fourth hour until $48 \mathrm{~h}$ postinjection. Sampling was done every $6 \mathrm{~h}$ thereafter until $72 \mathrm{~h}$ post-injection and once during each visit thereafter. Plasma concentrations of NNC126-0083 were analysed by York Bioanalytical Solutions Ltd, York, UK, using a validated sandwich-ELISA. NNC126-0083 was measured using an NNC126-0083-specific sandwich ELISA using a specific anti-NNC126-0083 capture antibody, a biotinylated anti-human hGH antibody as the detection antibody, a streptavidin-HRP conjugate as the enzyme label and tetramethylbenzidine $/ \mathrm{H}_{2} \mathrm{O}_{2}$ as the enzyme substrates. The peg-GH assay showed no crossreactivity with endogenous or rhGH (Norditropin). Serum concentrations of hGH, IGF1 and IGF-binding protein 3 (IGFBP3) were analysed by LKF Laboratorium für Klinische Forschung GmbH, Kiel, Germany, using commercially available assay kits (Immulite 2000 chemiluminescence immunoassay from Siemens Healthcare Diagnostics, Deerfield, IL, USA).

Sampling for the analysis of induction of antibodies was performed prior to injection at the day of the first treatment administration, at the visit scheduled 10 days thereafter and at the final visit scheduled 27-31 days after the first treatment administration. Antibodies against $\mathrm{NNC126-0083} \mathrm{and} \mathrm{GH} \mathrm{were} \mathrm{analysed} \mathrm{by} \mathrm{two}$ separate validated bridging ELISAs developed and performed by Novo Nordisk A/S (Maaloev, Denmark). Blood samples for the measurement of antibodies against NNC126-0083 and against hGH were collected: prior to dosing with NNC126-0083, 10 days after 
dosing with NNC126-0083 and at the follow-up visit. Determination of antibodies towards NNC126-0083 in serum was performed by screening samples with a bridging ELISA developed by Novo Nordisk A/S that detects antibodies that bind to NNC126-0083. Antibody specificity to either NNC126-0083 or hGH was analysed by a competitive inhibition test in which samples, which were positive in the screening assay, were analysed with and without pre-incubation with either NNC126-0083 or hGH. Antibody responses were furthermore characterised for in vitro neutralising effect using a BAF3 cell-based proliferation assay. The BAF3 cells were stably transfected with hGHR, resulting in dependence on either NNC126-0083 or hGH for growth and survival. The cell line shows a dose-related stimulation of proliferation by adding increasing concentrations of hGH or hGH analogues. An antibody response would be characterised as in vitro neutralising if it inhibits cell proliferation. Any subject with a blood sample positive for antibodies against NNC126-0083 was followed until an antibody-negative blood sample had been obtained. Samples positive for antibodies against NNC126-0083 and/or GH were further characterised for neutralising antibodies against NNC1260083 and/or GH, using a validated in vitro cell-based assay developed by Novo Nordisk A/S.

\section{$P K$ and PD analysis}

The PK endpoints were based on the plasma/serum concentrations of NNC126-0083 and GH determined after one administration of NNC126-0083 or after once-daily administration of $\mathrm{GH}$ for 7 days. The derived PK endpoints included the area under the plasma/ serum concentration curve versus time (area under the curve, AUC) (NNC126-0083: $\mathrm{AUC}_{0-168 \mathrm{~h}}$; GH: $\mathrm{AUC}_{\mathrm{O}-24 \mathrm{~h}}$ ), the maximum plasma/serum concentration $\left(C_{\text {max }}\right)$, the time to maximum plasma/serum concentration $\left(t_{\max }\right)$ and the terminal half-life $\left(t_{1 / 2}\right)$. For NNC126-0083, dose proportionality of AUC, $\mathrm{AUC}_{0-168 \mathrm{~h}}$, AUC and $C_{\max }$ was investigated by estimating the slope in the linear regression models of $\log (\mathrm{AUC}), \log \left(\mathrm{AUC}_{0-168 \mathrm{~h}}\right)$ and $\log \left(C_{\max }\right)$, respectively, versus $\log ($ dose $)$ with the dose expressed as $\mathrm{mg}$ protein $/ \mathrm{kg}$. A slope $\beta=1$ meant that the PK was dose proportional. The estimated quantity $2^{\beta}$, corresponding to the factor needed for calculation of the expected area obtained after doubling of the dose, was described with 95\% confidence intervals (CIs).

The PD endpoints were based on serum concentrations of IGF1 and IGFBP 3 up to $168 \mathrm{~h}$ after first trial product administration. The parameters were determined after one administration of NNC126-0083 or after once-daily administration of $\mathrm{GH}$ for 7 days. The derived $\mathrm{PD}$ endpoints included $C_{\max }, \mathrm{AUC}_{\mathrm{O}-168 \mathrm{~h}}$ and $\mathrm{AUC}_{0-168 \mathrm{~h}} / 168 \mathrm{~h}$, defined as the area under the profile in the interval $0-168 \mathrm{~h}$ after (first) trial product administration divided by $168 \mathrm{~h}$. $\mathrm{AUC}_{\mathrm{O}-168 \mathrm{~h}} / 168 \mathrm{~h}$ represents the average value observed during the interval 0-168 $\mathrm{h}$ while still encompassing all the information of $\mathrm{AUC}_{0-168 \mathrm{~h}}$ for the statistical comparison between dose groups, as $\mathrm{AUC}_{\mathrm{O}-168 \mathrm{~h}}$ is just divided by a constant in the derivation of this parameter. The benefit is a more easily interpretable parameter with the same scale as the raw values from which it is derived. For $C_{\max }$ and $\mathrm{AUC}_{\mathrm{O}-168 \mathrm{~h}} / 168 \mathrm{~h}$, comparisons between each of the NNC126-0083 doses and GH were performed using an ANOVA model with treatment as a factor and the pre-dose value (first dose) as a covariate. Values for $\mathrm{AUC}_{0-168 \mathrm{~h}} / 168 \mathrm{~h}, C_{\max }$ and the pre-dose value were log-transformed in the analysis. For each NNC1260083 dose, estimated mean ratios (mean differences for SDS) versus $\mathrm{GH}$ were estimated from the model together with $95 \%$ CIs. To investigate the steady state of $\mathrm{GH}$, the ratios for the IGF1 concentrations from each dosing until $24 \mathrm{~h}$ post-dose were calculated for every two consecutive injections of $\mathrm{GH}$.

\section{Results \\ Baseline characteristics}

A total of 31 subjects were randomised to treatment with either NNC126-0083 (23 subjects) or GH (eight subjects). One subject who was randomised to be treated with NNC126-0083 withdrew due to personal reasons. All 30 exposed subjects completed the trial and were included in both the safety and the PK/PD analysis sets. Only three subjects were exposed in the $0.01 \mathrm{mg} / \mathrm{kg}$ group, as opposed to the planned at least five. This was due to a dilution error, two subjects randomised to $0.01 \mathrm{mg} / \mathrm{kg}$ received $0.02 \mathrm{mg} / \mathrm{kg}$ instead (Table 1), and were thus allocated to the $0.02 \mathrm{mg} / \mathrm{kg}$ group (resulting in eight subjects in the $0.02 \mathrm{mg} / \mathrm{kg}$ group and three subjects in the $0.01 \mathrm{mg} / \mathrm{kg}$ group). One subject $(0.04 \mathrm{mg} / \mathrm{kg})$ was randomised but withdrawn before exposure resulting in five subjects in this dose group. Subject baseline characteristics are presented in Table 1. All subjects were assessed as pre-pubertal at baseline and considered representative for children with GHD.

\section{PK profile of NNC126-0083}

Three subjects randomised to $0.01 \mathrm{mg}$ protein $/ \mathrm{kg}$ were accidentally administered erroneous doses: two subjects received $0.02 \mathrm{mg}$ protein $/ \mathrm{kg}$ and were allocated to dose level $0.02 \mathrm{mg}$ protein $/ \mathrm{kg}$ and one subject received $0.0146 \mathrm{mg}$ protein $/ \mathrm{kg}$ and was retained within dose level $0.01 \mathrm{mg}$ protein $/ \mathrm{kg}$, with the exception of the dose proportionality analysis, where the actual dose level $0.0146 \mathrm{mg}$ protein $/ \mathrm{kg}$ was used. All exposed subjects were included in the full analysis set, and all PK profiles were considered valid for the calculation of all PK endpoints. The mean PK profiles after administration of 
Table 1 Baseline characteristics at screening of subjects. Values are median (range) or as specified.

\begin{tabular}{|c|c|c|c|c|c|}
\hline & \multicolumn{4}{|c|}{ NNC126-0083 dose level (mg/kg) } & \multirow{2}{*}{$\begin{array}{c}\mathrm{GH}(\mathrm{mg} / \mathrm{kg}) \\
0.035\end{array}$} \\
\hline & 0.01 & 0.02 & 0.04 & 0.06 & \\
\hline$n$ & 3 & 8 & 5 & 6 & 8 \\
\hline Sex (M:F) & $3: 0$ & $6: 2$ & $3: 2$ & $4: 2$ & $6: 2$ \\
\hline Age (years) & $10.8(6.5$ to 11.6$)$ & 9.8 (6.2 to 11.7$)$ & $10.3(7.8$ to 12.6$)$ & $7.8(6.9$ to 11.7$)$ & 8.5 (5.9 to 10.6$)$ \\
\hline Height $(m)$ & 1.34 (1.26 to 1.45$)$ & 1.32 (0.99 to 1.42$)$ & 1.26 (1.08 to 1.37$)$ & 1.20 (1.01 to 1.33$)$ & 1.26 (1.07 to 1.36$)$ \\
\hline Height SDS & $-0.26(-1.30$ to 1.38$)$ & $-0.99(-3.37$ to 1.24$)$ & $-2.27(-3.85$ to -0.66$)$ & $-2.07(-3.95$ to 0.93$)$ & $-0.98(-1.76$ to 2.04$)$ \\
\hline BMI $\left(\mathrm{kg} / \mathrm{m}^{2}\right)$ & 17.7 (14.9 to 24.0$)$ & $18.2(14.7$ to 32.8$)$ & $14.9(14.5$ to 16.6$)$ & $16.7(13.9$ to 21.4$)$ & 18.7 (13.5 to 23.2$)$ \\
\hline BMI SDS & $1.45(-1.27$ to 2.20$)$ & $1.26(-1.72$ to 4.37$)$ & $-0.83(-1.40$ to -0.08$)$ & $0.64(-1.37$ to 1.72$)$ & $1.37(-2.18$ to 3.59$)$ \\
\hline \multicolumn{6}{|l|}{ IGF1 at pre-dose day 1} \\
\hline ng/ml (mean (range)) & 60.8 (12.5 to 107.0$)$ & 105.3 (44.0 to 176.0 ) & 152.0 (44.0 to 326.0 ) & 42.0 (12.5 to 88.0$)$ & 113.9 (42.0 to 297.0 ) \\
\hline SDS (mean (min, max)) & $-3.7(-7.1,-0.3)$ & $-1.4(-2.4,-0.1)$ & $-1.4(-4.0,0.4)$ & $-3.6(-7.8,-0.9)$ & $-1.2(-3.2,2.1)$ \\
\hline
\end{tabular}

$\mathrm{F}$, female; $\mathrm{M}$, male; BMI, body mass index.

NNC126-0083 or GH are displayed in Fig. 1. The mean concentrations of NNC126-0083 were initially increased in a dose-dependent manner and substantially decreased by $72 \mathrm{~h}$ post-dose. Diurnal variations in the PK profile were observed for all cohorts and best visualised on a linear scale (Fig. 1B). The derived PK endpoints $\mathrm{AUC}_{0-168 \mathrm{~h}}, C_{\max }, t_{\max }$ and $t_{1 / 2}$ after administration of NNC126-0083 or GH are displayed in Table 2. The systemic exposure after a single s.c. dose of NNC126-0083, as measured by the mean $\mathrm{AUC}_{0-168 \mathrm{~h}}$ and $C_{\max }$, increased with the dose. A more than doseproportional exposure, likely to indicate saturated clearance of the drug, was observed for the highest dose levels of 0.04 and $0.06 \mathrm{mg}$ protein $/ \mathrm{kg}$, with estimated slopes for $\mathrm{AUC}_{0-168 \mathrm{~h}}=1.30, \mathrm{AUC}=1.35$ and $C_{\max }=1.56$. However, none of the deviations from dose proportionality was statistically significant (for AUC $_{0-168 \mathrm{~h}}: P=0.26(\mathrm{CI}=1.69,3.57)$; AUC: $P=0.36$ $\left.(\mathrm{CI}=1.62,3.51) ; C_{\text {max }}: P=0.09(\mathrm{CI}=1.87,4.62)\right)$.

\section{PD parameters}

All PD profiles were considered valid for the calculation of all PD endpoints. Four subjects had in total 18 measurements ( $6 \%$ of the total recordings) below the lower level of quantification $(25 \mathrm{ng} / \mathrm{ml})$, and these values were set to a default value of $\mathrm{LLOQ} / 2$ $(12.5 \mathrm{ng} / \mathrm{ml})$.

Notable inter-subject variation of the IGF1 levels $(\mathrm{ng} / \mathrm{ml})$ at baseline (timepoint zero) was observed in all cohorts (Table 1 and Fig. 2). The baseline values were therefore also subtracted and the resulting mean IGF1 profiles are displayed in Fig. 3. As expected, initial decreases in the mean IGF1 levels were observed as a consequence of the GH washout. The IGF1 SDS were markedly different between the groups pre-dose, which could presumably alter the maximum response possible. It is possible that insufficient washout of previous hGH treatment might have contributed to some of the high baseline values observed and to the difference in baseline IGF1 SDS between the groups.
After administration of NNC126-0083 or GH, mean levels of IGF1 were increased in response to treatment. For the three highest NNC126-0083 dose levels, 0.02, 0.04 and $0.06 \mathrm{mg}$ protein $/ \mathrm{kg}$, the mean IGF $1 C_{\max }$ values were comparable to those recorded prior to the $\mathrm{GH}$ washout. The greatest increase in mean IGF1 level $(\mathrm{ng} / \mathrm{ml})$ from baseline was observed for cohort $0.06 \mathrm{mg}$ protein $/ \mathrm{kg}$, with estimated mean (S.D.) values for $C_{\max }$ : $172.7(109.8) \mathrm{ng} / \mathrm{ml}$ and $\mathrm{AUC}_{0-168 \mathrm{~h}} / 168 \mathrm{~h}: 97.5$ (52.3) $\mathrm{ng} / \mathrm{ml}$. This was also reflected for IGF1 SDS, with cohort $0.06 \mathrm{mg}$ protein $/ \mathrm{kg}$ reaching greatest increase from baseline, with estimated mean values (s.D.) for $C_{\text {max }}$ : $-0.0(1.8)$ SDS and $\mathrm{AUC}_{0-168 \mathrm{~h}} / 168 \mathrm{~h}$ : -1.8 (1.8) SDS. The IGF1 levels subsided with time but increased again on resumption of standard GH

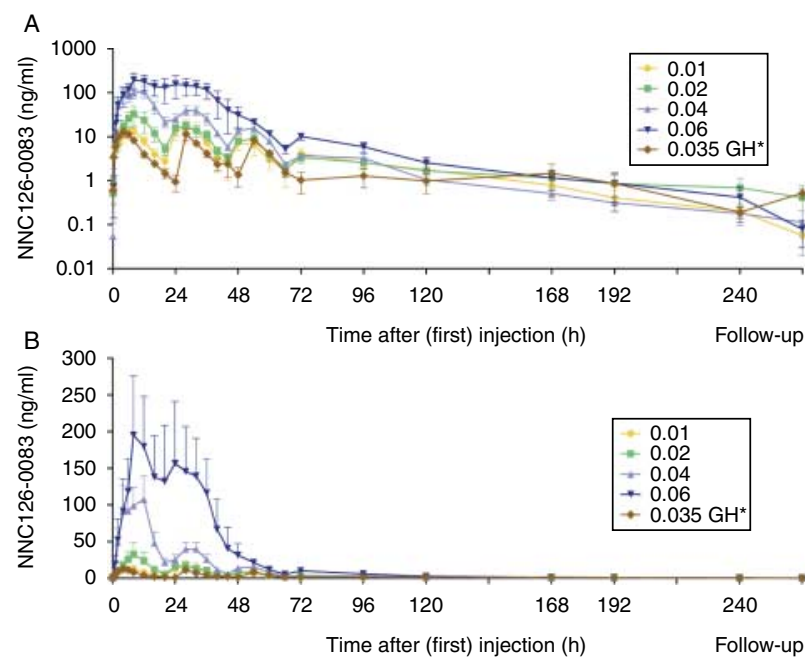

Figure 1 Mean concentrations ( \pm S.E.M.) of NNC126-0083 (ng protein/ml) in plasma and GH ( \pm s.E.M.) $(\mathrm{ng} / \mathrm{ml})$ in serum after treatment of children with GHD. In addition to a logarithmic scale (A), concentrations are displayed on a linear scale (B) to illustrate the diurnal fluctuations in concentrations. The asterisk $\left(\mathrm{GH}^{\star}\right)$ indicates that concentrations of GH were measured instead of NNC126-0083. The mean concentrations of NNC126-0083 were initially increased in a dose-dependent manner and substantially decreased by $72 \mathrm{~h}$ post-dose. 
Table 2 Summary of pharmacokinetic endpoints after administration of NNC126-0083 or GH to children with GH deficiency. Data are presented as mean (s.D.) values.

\begin{tabular}{|c|c|c|c|c|c|}
\hline $\begin{array}{l}\text { NNC126-0083 } \\
\text { (mg protein/kg) }\end{array}$ & $n$ & $\underset{(\mathrm{h} \times \mathrm{ng} \text { protein } / \mathrm{kg})}{\text { AUC }_{0-168}}$ & $\underset{\text { (ng protein/ml) }}{\boldsymbol{C}_{\max }}$ & $t_{\max }(\mathrm{h})$ & $t_{1 / 2}(\mathrm{~h})$ \\
\hline 0.01 & 3 & $692.2(376.7)$ & $18.1(12.8)$ & 22.7 (12.9) & $36.3(10.7)$ \\
\hline 0.02 & 8 & $960.2(663.1)$ & $35.9(43.7)$ & $17.0(16.8)$ & $68.2(71.7)$ \\
\hline 0.04 & 5 & 2450.9 (1198.0) & $124.5(79.0)$ & $8.8(3.3)$ & $32.5(14.5)$ \\
\hline 0.06 & 6 & $6348.8(6085.4)$ & 219.7 (189.8) & $19.4(12.5)$ & $31.2(13.2)$ \\
\hline $0.035(\mathrm{GH})$ & 8 & $897.5(198.1)^{a}$ & $14.22(8.1)$ & $5.3(1.5)$ & $5.7(3.5)$ \\
\hline
\end{tabular}

${ }^{a}$ For $\mathrm{GH}, \mathrm{AUC}_{0-168 \mathrm{~h}}$ was calculated as $7 \times \mathrm{AUC}_{0-24 \mathrm{~h}}(\mathrm{~h} \times \mathrm{ng} / \mathrm{kg})$.

treatment at $240 \mathrm{~h}$ (Fig. 2). When analysing the dose-response relationship for $\mathrm{AUC}_{0-168 \mathrm{~h}} / 168 \mathrm{~h}$ and $C_{\max }$ values (baseline not subtracted), no relationship was evident for the estimated mean $\mathrm{AUC}_{0-168 \mathrm{~h}} / 168 \mathrm{~h}$ values (IGF $1 \mathrm{ng} / \mathrm{ml}$ and SDS), whereas a dose-response relationship was evident for $C_{\max }$ values (IGF1 $\mathrm{ng} / \mathrm{ml}$ and SDS) (data not shown). The IGF1 mean exposure obtained in the $\mathrm{NNC126-0083} 0.06 \mathrm{mg}$ protein $/ \mathrm{kg}$ cohort increased earlier compared with the GH cohort and began subsiding at $\sim 3$ days post-dose (Fig. 2). Statistical comparisons between the average IGF1 exposure for the $\mathrm{NNC126-0083} \mathrm{cohort} \mathrm{profiles} \mathrm{and}$ the GH cohort profile (baselines not subtracted) showed no statistically significant differences between the estimated mean values $\left(\mathrm{AUC}_{0-168 \mathrm{~h}} / 168 \mathrm{~h}\right.$ and $C_{\max }$; both in $\mathrm{ng} / \mathrm{ml}$ and SDS) for the GH cohort and $\mathrm{NNC126-0083}$ cohort $0.06 \mathrm{mg}$ protein $/ \mathrm{kg}$. When comparing estimated mean values for
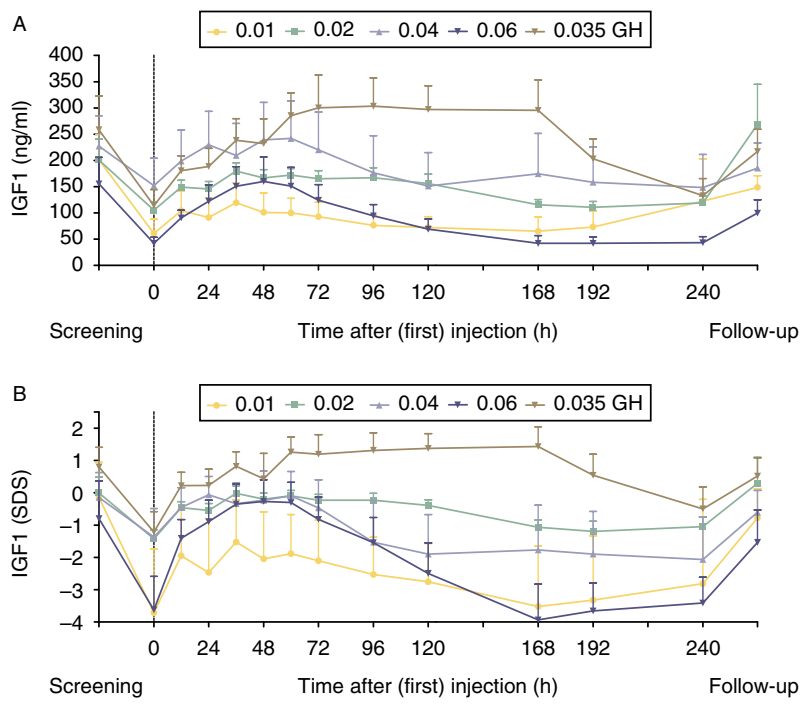

Figure 2 Mean levels ( \pm s.E.M.) of IGF1 $\mathrm{ng} / \mathrm{ml}(\mathrm{A})$ and IGF1 SDS (B) versus time after treatment of children with GHD. After administration of NNC126-0083 or GH, mean levels of IGF1 were increased in response to treatment. For the three highest NNC126-0083 dose levels, the mean IGF1 $C_{\max }$ values were comparable to those recorded prior to the $\mathrm{GH}$ washout. A statistically significant dose-response relationship was observed for $C_{\max }$ but not for $\mathrm{AUC}_{0-168 \mathrm{~h}} / 168 \mathrm{~h}$.
NNC126-0083 dose levels below $0.06 \mathrm{mg}$ protein $/ \mathrm{kg}$ with the estimated mean values for the $\mathrm{GH}$ cohort, the latter were significantly higher $(P \leq 0.05)$, with the exception of IGF1 $C_{\max }(\mathrm{ng} / \mathrm{ml})$ for NNC126-0083 cohort $0.04 \mathrm{mg}$ protein $/ \mathrm{kg}$, for which there was no statistically significant difference (data not shown).

Initial decreases in IGFBP3 levels, resulting from the GH washout, were observed. After administration of NNC126-0083 or GH, mean levels of IGFBP3 increased in response to treatment (Fig. 4). The IGF1/IGFBP3 molar ratios were calculated as previously described (11) (data not shown). The greatest increase in mean IGFBP3 level $(\mathrm{ng} / \mathrm{ml})$ from baseline was observed for cohort $0.06 \mathrm{mg}$ protein $/ \mathrm{kg}$, with mean (s.D.) values for $C_{\max }: 3.4(0.54) \mathrm{mg} / \mathrm{ml}$ and $\mathrm{AUC}_{0-168 \mathrm{~h}} / 168 \mathrm{~h}: 2.68$ (0.55) $\mathrm{mg} / \mathrm{ml}$. When analysing the dose-response relationship for $\mathrm{AUC}_{0-168} / 168 \mathrm{~h}$ and $C_{\max }$ values (baseline not subtracted), no relationship was evident for the estimated mean values for $\mathrm{AUC}_{0-168 \mathrm{~h}} / 168 \mathrm{~h}$ and $C_{\max }$ (IGFBP $3 \mathrm{ng} / \mathrm{ml}$ and SDS), with the exception for IGFBP3 SDS $C_{\max }$, for which dose-response was apparent (data not shown). The estimated mean values for IGFBP $3 \mathrm{AUC}_{0-168 \mathrm{~h}} / 168 \mathrm{~h}$ and IGFBP $3 C_{\max }(\mathrm{ng} / \mathrm{ml}$ and SDS) for the GH and NNC126-0083 cohorts were comparable, with the exception of values for $\mathrm{AUC}_{0-168 \mathrm{~h}} / 168 \mathrm{~h}(\mathrm{ng} / \mathrm{ml})$ and $C_{\text {max }}(\mathrm{ng} / \mathrm{ml}$ and SDS $)$ for the $\mathrm{NNC126-0083} 0.01 \mathrm{mg}$ protein $/ \mathrm{kg}$ cohort, which were significantly lower in comparison to the GH cohort (data not shown).

\section{Safety}

NNC126-0083 was well tolerated in children with GHD. A total of 22 adverse events were reported in 15 of the 30 subjects after exposure to $\mathrm{NNC126-0083} \mathrm{or} \mathrm{GH}$. The majority of the adverse events $(20 / 22)$ were mild in severity, and two events were of moderate severity. There were no apparent differences in the number and type of adverse events between NNC126-0083 and GH treatment, or between the NNC126-0083 cohorts. No deaths or serious adverse events were reported during the trial. No subjects were withdrawn due to adverse events. A full recovery was observed for all 22 adverse events reported. Two adverse events were evaluated as possibly or probably related to treatment with NNC126-0083: one event of pancytopenia (cohort 

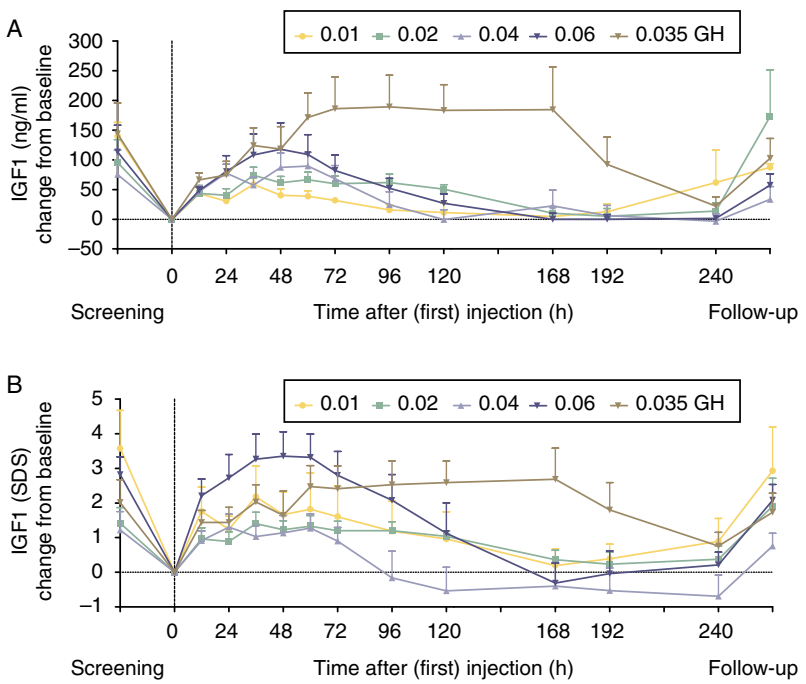

Figure 3 Changes from baseline in the mean levels ( \pm S.E.M.) of IGF1 $\mathrm{ng} / \mathrm{ml}(\mathrm{A})$ and IGF1 SDS (B) versus time after treatment of children with GHD. Following administration of NNC126-0083, the greatest increase in mean IGF1 from baseline was observed for cohort $0.06 \mathrm{mg} / \mathrm{kg}$.

$0.06 \mathrm{mg}$ protein $/ \mathrm{kg}$ ) and one injection site reaction (cohort $0.04 \mathrm{mg}$ protein $/ \mathrm{kg}$ ). As for the pancytopenia event, it was recorded the day after treatment injection and was mild, transient (duration: 2 days), and according to the investigator possibly a result of a viral infection (which was not recorded as an adverse event). Alternatively, the adverse events could be ascribed to a partially clothed sample. No other adverse events were reported for this subject.

A total of three subjects experienced mild injection site reactions, two subjects in cohort NNC126-0083 $0.04 \mathrm{mg}$ protein $/ \mathrm{kg}$ and one subject in cohort NNC126$00830.06 \mathrm{mg}$ protein $/ \mathrm{kg}$. Redness at the injection site was reported in the three cases, with sizes ranging from 0.2 to $10 \mathrm{~mm}$. For one subject, a mild induration (size $1 \mathrm{~mm}$ ) was also noted, and this event was reported as an adverse event possibly related to the trial product. The maximum duration of the injection site reactions ranged approximately from 6 to $48 \mathrm{~h}$, and all findings resolved during the trial. No lipoatrophy was observed during the trial in any of the subjects.

Initial decreases within the reference range in the mean haemoglobin levels were observed for all treatment groups including $\mathrm{GH}$, which may be attributed to blood sampling. Individual haemoglobin levels below normal were observed for two subjects in cohort $0.02 \mathrm{mg}$ protein $/ \mathrm{kg}$ (at 7 and 10 days post-dose and 3 days post-dose, respectively): two subjects in cohort $0.04 \mathrm{mg}$ protein $/ \mathrm{kg}$ (levels below normal at pre-dose) and three subjects in cohort $0.06 \mathrm{mg}$ protein $/ \mathrm{kg}$, at the measurements 1 and 3 days, 3 days and 7 days postdose, respectively. From these three subjects in cohort
$0.06 \mathrm{mg}$ protein $/ \mathrm{kg}$, only one subject experienced an $\mathrm{AE}$ (mild) reported as pancytopenia during the trial. In this subject, parameters returned to normal after a few days. Two increased glucose levels were recorded at the day after initiation of treatment in cohorts NNC126-0083 $(0.06 \mathrm{mg}$ protein $/ \mathrm{kg}$ ) and $\mathrm{GH}$, respectively.

Transient antibodies against NNC126-0083 were detected in one sample from one subject in the lowest dose group of $0.01 \mathrm{mg}$ protein $/ \mathrm{kg}$, collected on day 11 . The sample was classified as 'weakly positive' (titre: 1) and was negative for cross-reactive antibodies against GH and neutralising antibodies (against NNC1260083). The antibody sample collected at the follow-up (28 days post-dose) was negative.

\section{Discussion}

GH replacement therapy currently requires daily injections, which may be both inconvenient and distressing for the young patient. NNC126-0083 is a long-acting GH preparation that has previously been shown to possess a potential once-weekly PK and PD treatment profile after single and multiple administration to healthy adults $(6,7)$ and multiple administrations to adults with GHD (8). The preparation utilises the prolongation of the in vivo mean residence time resulting from pegylation, a strategy that has successfully been applied to several drugs approved for human use (12-14). This study examined the short-term safety, tolerability, PK and PD profiles of single s.c. doses of NC126-0083 administered to children with GHD. NNC126-0083 was well tolerated at all dose levels investigated. For the three highest $\mathrm{NNC126-0083} \mathrm{dose}$ levels, $0.02,0.04$ and $0.06 \mathrm{mg}$ protein $/ \mathrm{kg}$, the mean
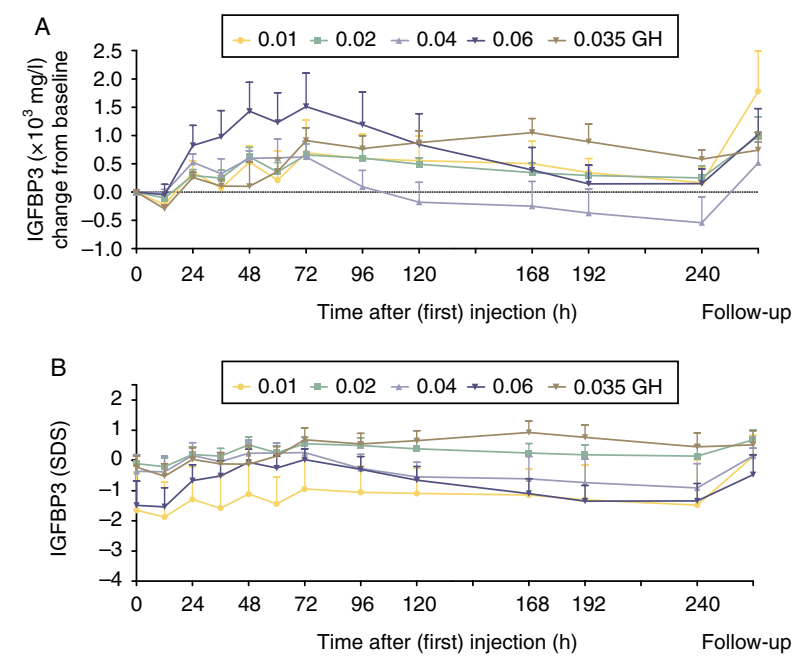

Figure 4 Mean levels ( \pm S.E.M.) of IGFBP3 $\mathrm{mg} / \mathrm{l}$ (change from baseline) (A) and IGFBP3 SDS (B) versus time after treatment of children with GHD. The greatest increase in mean IGFBP3 level $(\mathrm{mg} / \mathrm{l})$ from baseline was observed for cohort $0.06 \mathrm{mg}$ protein $/ \mathrm{kg}$. 
$C_{\text {max }}$ values for IGF1 ( $\mathrm{ng} / \mathrm{ml}$ and SDS) were similar to those recorded prior to the washout of rhGH. The IGF1 levels observed prior to the hGH washout were within the normal range for all groups; however, a marked difference in pre-dose IGF1 SDS was present between groups and it cannot be ruled out that the different IGF1 SDS between the groups pre-dose impacted the maximum IGF1 response possible. A marked difference in the baseline corrected screening IGF1 SDS and IGF1 levels was present between groups. The baseline corrected screening IGF1 value reflects the change in IGF1 after the hGH washout and therefore the observed pre-dose IGF1 SDS difference may likely be ascribed to a heterogeneous response to washout of rhGH or alternatively lack of compliance with being off hGH replacement for the entire washout period. The latter may also explain why some IGF1 levels were quite normal in some of the patients after hGH washout, although normal IGF1 levels can occur in some GHD. The systemic exposure, as measured by the AUC and $C_{\text {max }}$, increased with the dose. The PK for NNC1260083 was similar to that observed in previous clinical trials enrolling adults $(n=6-8)$, with a tendency towards a higher level of exposure in children. A comparison of the data obtained in NNC126-0083 and the GH cohort showed no statistically significant difference between the estimated IGF $1 \mathrm{AUC}_{0-168 \mathrm{~h}} / 168 \mathrm{~h}$ or IGF1 $C_{\max }$ mean values for the $\mathrm{GH}$ cohort and NNC126-0083 cohort $0.06 \mathrm{mg}$ protein $/ \mathrm{kg}$. Both the estimated mean average exposure and $C_{\max }$ values were higher for the $\mathrm{GH}$ cohort when comparing with the lower NNC126-0083 dose levels investigated. However, it should be noted that a stringent comparison between the PK for NNC126-0083 and Norditropin is not possible for several reasons. First, the two treatments are associated with separate dosing regimens (singledose versus multiple-dose), with different PK profiles as a consequence. Secondly, the intrinsic differences between the two assays measuring plasma/serum concentrations of NNC126-0083 and GH do not allow direct comparisons of the exposure other than between NNC126-0083 cohorts. Thirdly, the relatively low number of subjects limited the statistical interpretation of the data, which was further complicated by great variations of the IGF1 baseline levels.

Diurnal variations in the PK profiles were observed in all cohorts. Similar variations were also observed in the previous trials with NNC126-0083 in healthy volunteers and adult GHD (6-8), and the reason for these fluctuations remains to be elucidated. As discussed in recent publications (6-8), it may be related to the diurnal variation of lymphatic drainage in the subcutaneous tissue, but this has yet to be verified. The typically observed PK profile for NNC126-0083 with its diurnal variations and the $\mathrm{PK}$ profile for daily $\mathrm{GH}$ injection with its characteristic peak and through $\mathrm{GH}$ levels over $24 \mathrm{~h} \mathrm{(15)}$ are both very different from the general profile of the normal physiological pulsatile
GH secretion (16). However, the efficacy of daily GH injections when treating adults and children with GHD has been confirmed in several clinical studies, with normalisation of growth rate (17), body composition $(18,19)$, bone metabolism (20) and other metabolic abnormalities associated with GHD. Studies on rats have reported the importance of $\mathrm{GH}$ pulsatility for various markers of GH action, including growth (21), and a limited number of short-term studies on humans comparing continuous infusion versus bolus injections of GH have shown some differential effects on very lowdensity lipoprotein, cholesterol, free fatty acids and lipoprotein(a) $(15,22-24)$. The vast majority of these differences were not confirmed in a longer term study of continuous GH infusion versus daily injections in adults with GHD (4), and a 6-month study on children with GHD did not observe any difference in growth when comparing continuous $\mathrm{GH}$ infusion versus daily injection ((5), indicating that $\mathrm{GH}$ replacement seems to be efficacious regardless of the administration mode in humans $(4,5)$. Sustained release $\mathrm{GH}$ preparations have been evaluated in longer term studies on both adults (25) and children $(26,27)$ and were assessed as being efficacious and safe, with no significant alterations in lipid metabolism and insulin resistance.

In summary, single dose of NNC126-0083 administered s.c. to children with GHD was well tolerated at all doses investigated (up to and including $0.06 \mathrm{mg}$ protein $/ \mathrm{kg}$ ) and was not associated with any safety issues; however, it has to be stressed that the safety profile only deals with acute administration in the current study and long-term metabolic effects cannot be extrapolated from these data. No accumulation of NNC126-0083, or clinically significant local tolerability issues, was observed at any dose level tested. Three injection site reaction was observed in the NNC126-0083 groups. No injection site reaction was observed in the daily hGH group; however, it has to be acknowledged that the number of subjects receiving once-weekly were three times larger than the daily hGH group. The three injection site reactions were mild, transient with short duration similar to injection site reactions observed with daily hGH. The two injection site reactions were not comparable to the injection site reactions (i.e. severe lipoatrophy) observed with other pegylated $\mathrm{GH}$ compounds.

At the three highest NNC126-0083 dose levels investigated $(0.02,0.04$ and $0.06 \mathrm{mg}$ protein $/ \mathrm{kg})$, the mean IGF1 $C_{\max }$ values were comparable to those recorded prior to the $\mathrm{GH}$ washout. At $0.06 \mathrm{mg}$ protein $/ \mathrm{kg}$, the resulting IGF1 response began subsiding at $\sim 3$ days post-dose. Furthermore, in previous studies, a satisfactory IGF1 profile was achieved with higher doses of NNC126-0083 in adults (6-8). Thus, higher dose levels than those investigated in this study may potentially have achieved an IGF1 profile suitable for once-weekly dosing in GHD children but such higher dose levels would also need to be explored with regard to safety. In conclusion, single doses of long-acting 
NNC126-0083 were safe and well tolerated in children with GHD. Increased IGF1 levels were observed for all NNC126-0083 and GH dose groups; however, a satisfactory once-weekly IGF1 profile was not reached within the NNC126-0083 dose levels administered.

\section{Declaration of interest}

M H Rasmussen is stockholder and employee of Novo Nordisk A/S.

\section{Funding}

This trial was sponsored by Novo Nordisk A/S. ClinicalTrials.gov registration number: NCT00936403. The study was supported financially by Novo Nordisk A/S.

\section{Acknowledgements}

The authors wish to acknowledge the other principal investigators: Prof. Jens Sandahl Christiansen (Denmark); Prof. Marc Nicolino and Prof. Maïthé Tauber (France); Prof. Eli Hershkovitz, Prof. Moshe Phillip, Dr David Zangen and Dr Nehama Zuckerman (Israel); Dr Antonio Carrascosa, Dr Ignacio Díez, Dr Lourdes Ibáñez and Dr Manuel Pombo (Spain); Dr Carlo Acerini and Prof. Timothy Barrett (UK); all sub-investigators and subjects participating, and Nina-Maria Vasconcelos who provided medical writing services on behalf of Novo Nordisk A/S.

\section{References}

1 Desrosiers P, O'Brien F \& Blethen S. Patient outcomes in the GHMonitor: the effect of delivery device on compliance and growth. Pediatric Endocrinology Reviews 20052 (Supplement 3) 327-331.

2 Kapoor RR, Burke SA, Sparrow SE, Hughes IA, Dunger DB, Ong KK \& Acerini CL. Monitoring of concordance in growth hormone therapy. Archives of Disease in Childhood 200893 147-148. (doi:10. 1136/adc.2006.114249)

3 Rosenfeld RG \& Bakker B. Compliance and persistence in pediatric and adult patients receiving growth hormone therapy. Endocrine Practice 200814 143-154.

4 Laursen T, Gravholt CH, Heickendorff L, Drustrup J, Kappelgaard AM, Jorgensen JO \& Christiansen JS. Long-term effects of continuous subcutaneous infusion versus daily subcutaneous injections of growth hormone $(\mathrm{GH})$ on the insulin-like growth factor system, insulin sensitivity, body composition, and bone and lipoprotein metabolism in GH-deficient adults. Journal of Clinical Endocrinology and Metabolism $2001 \quad 86 \quad 1222-1228$. (doi:10.1210/jc.86.3.1222)

5 Tauber M, De Bouet Du PH, Sallerin-Caute B, Rochiccioli P \& Bastide R. Differential regulation of serum growth hormone $(\mathrm{GH})$ binding protein during continuous infusion versus daily injection of recombinant human GH in GH-deficient children. Journal of Clinical Endocrinology and Metabolism $1993 \quad \mathbf{7 6} \quad 1135-1139$. (doi:10.1210/jc.76.5.1135)

6 Rasmussen MH, Jensen L, Anderson TW, Klitgaard T \& Madsen J. Multiple doses of pegylated long-acting growth hormone is well tolerated in healthy male volunteers and possesses a potential once-weekly treatment profile. Clinical Endocrinology $2010 \mathbf{7 3}$ 769-776. (doi:10.1111/j.1365-2265.2010.03863.x)

7 Rasmussen MH, Bysted BV, Anderson TW, Klitgaard T \& Madsen J. Pegylated long-acting human growth hormone is well-tolerated in healthy subjects and possesses a potential once-weekly pharmacokinetic and pharmacodynamic treatment profile. Journal of Clinical Endocrinology and Metabolism $2010 \quad 95$ 3411-3417. (doi:10.1210/jc.2009-2813)
8 Søndergaard E, Klose M, Hansen M, Hansen BS, Andersen M, Feldt-Rasmussen U, Laursen T, Rasmussen MH \& Christiansen JS. Pegylated long-acting human growth hormone possesses a promising once-weekly treatment profile and multiple-dosing is well-tolerated in adult patients with growth hormone deficiency. Journal of Clinical Endocrinology and Metabolism 201096 681-688. (doi:10.1210/jc.2010-1931)

91996 International Conference on Harmonisation, harmonised tripartite guideline: guideline for good clinical practice E6(R1), 1996. ICH secretariat, Geneva, Switzerland.

10 World medical association declaration of Helsinki. Ethical principles for medical research involving human subjects. Adopted by the 18th WMA General Assembly, Helsinki, Finland, June 1964; latest amendment made by the 59th WMA General Assembly, Seoul, October 2008.

11 Juul A, Dalgaard P, Blum WF, Bang P, Hall K, Michaelsen KF, Muller J \& Skakkebaek NE. Serum levels of insulin-like growth factor (IGF)-binding protein-3 (IGFBP-3) in healthy infants, children, and adolescents: the relation to IGF-I, IGF-II, IGFBP-1, IGFBP-2, age, sex, body mass index, and pubertal maturation. Journal of Clinical Endocrinology and Metabolism $1995 \mathbf{8 0}$ 2534-2542. (doi:10.1210/jc.80.8.2534)

12 Veronese FM \& Pasut G. PEGylation, successful approach to drug delivery. Drug Discovery Today 200510 1451-1458. (doi:10. 1016/S1359-6446(05)03575-0)

13 Webster R, Didier E, Harris P, Siegel N, Stadler J, Tilbury L \& Smith D. PEGylated proteins: evaluation of their safety in the absence of definitive metabolism studies. Drug Metabolism and Disposition 200735 9-16. (doi:10.1124/dmd.106.012419)

14 Hamidi M, Rafiei P \& Azadi M. Designing PEGylated therapeutic molecules: advantages in ADMET properties. Expert Opinion on Drug Discovery 200811 1293-1307. (doi:10.1517/17460441.3. 11.1293)

15 Laursen T, Jorgensen JO, Jakobsen G, Hansen BL \& Christiansen JS. Continuous infusion versus daily injections of growth hormone $(\mathrm{GH})$ for 4 weeks in GH-deficient patients. Journal of Clinical Endocrinology and Metabolism 199580 2410-2418. (doi:10.1210/jc.80.8.2410)

16 Iranmanesh A, Grisso B \& Veldhuis JD. Low basal and persistent pulsatile growth hormone secretion are revealed in normal and hyposomatotropic men studied with a new ultrasensitive chemiluminescence assay. Journal of Clinical Endocrinology and Metabolism 199478 526-535. (doi:10.1210/jc.78.3.526)

17 Reiter EO, Price DA, Wilton P. Albertsson-Wikland K \& Ranke MB. Effect of growth hormone $(\mathrm{GH})$ treatment on the near-final height of 1258 patients with idiopathic GH deficiency: analysis of a large international database. Journal of Clinical Endocrinology and Metabolism 200691 2047-2054. (doi:10.1210/jc.2005-2284)

18 Jorgensen JO, Pedersen SA, Thuesen L, Jorgensen J, IngemannHansen T, Skakkebaek NE \& Christiansen JS. Beneficial effects of growth hormone treatment in GH-deficient adults. Lancet 19891 1221-1225. (doi:10.1016/S0140-6736(89)92328-3)

19 van der Klaauw AA, Romijn JA, Biermasz NR, Smit JW, van Doorn J, Dekkers OM, Roelfsema F \& Pereira AM. Sustained effects of recombinant $\mathrm{GH}$ replacement after 7 years of treatment in adults with GH deficiency. European Journal of Endocrinology 2006 155 701-708. (doi:10.1530/eje.1.02283)

20 Bex M, Abs R, Maiter D, Beckers A, Lamberigts G \& Bouillon R. The effects of growth hormone replacement therapy on bone metabolism in adult-onset growth hormone deficiency: a 2-year open randomized controlled multicenter trial. Journal of Bone and Mineral Research 200217 1081-1094. (doi:10.1359/jbmr.2002. 17.6.1081)

21 Laursen T. Clinical pharmacological aspects of growth hormone administration. Growth Hormone \& IGF Research 200414 16-44. (doi:10.1016/j.ghir.2003.10.001)

22 Johansson JO, Oscarsson J, Bjarnason R \& Bengtsson BA. Two weeks of daily injections and continuous infusion of recombinant human growth hormone $(\mathrm{GH})$ in $\mathrm{GH}$-deficient adults: I. Effects on insulin-like growth factor-I (IGF-I), GH and IGF binding proteins, and glucose homeostasis. Metabolism 199645 362-369. (doi:10. 1016/S0026-0495(96)90292-9) 
23 Oscarsson J, Ottosson M, Johansson JO, Wiklund O, Marin P, Bjorntorp P \& Bengtsson BA. Two weeks of daily injections and continuous infusion of recombinant human growth hormone (GH) in GH-deficient adults. II. Effects on serum lipoproteins and lipoprotein and hepatic lipase activity. Metabolism $1996 \mathbf{4 5}$ 370-377. (doi:10.1016/S0026-0495(96)90293-0)

24 Laursen T, Lemming L, Jorgensen JO, Klausen IC \& Christiansen JS Different effects of continuous and intermittent patterns of growth hormone administration on lipoprotein levels in growth hormonedeficient patients. Hormone Research 199850 284-291. (doi:10. 1159/000023292)

25 Reiter EO, Attie KM, Moshang T Jr, Silverman BL, Kemp SF, Neuwirth RB, Ford KM \& Saenger P. A multicenter study of the efficacy and safety of sustained release $\mathrm{GH}$ in the treatment of naive pediatric patients with GH deficiency. Journal of Clinical Endocrinology and Metabolism 200186 4700-4706. (doi:10. $1210 /$ jc. 86.10 .4700$)$
26 Silverman BL, Blethen SL, Reiter EO, Attie KM, Neuwirth RB \& Ford KM. A long-acting human growth hormone (Nutropin Depot): efficacy and safety following two years of treatment in children with growth hormone deficiency. Journal of Pediatric Endocrinology and Metabolism 200215 (Supplement 2) 715-722. (doi:10.1515/JPEM.2002.15.S2.715)

27 Hoffman AR, Biller BM, Cook D, Baptista J, Silverman BL, Dao L, Attie KM, Fielder P, Maneatis T \& Lippe B. Efficacy of a long-acting growth hormone $(\mathrm{GH})$ preparation in patients with adult $\mathrm{GH}$ deficiency. Journal of Clinical Endocrinology and Metabolism 2005 90 6431-6440. (doi:10.1210/jc.2005-0928)

Received 16 June 2011

Accepted 1 July 2011 